\title{
Experimental studies on re-hydration of vacuum freeze-dried (Asparagus officinalis L.) with a hydrophilic substance
}

\author{
Fahim Ullah ${ }^{1^{*}}$
}

1. Joint International Research Laboratory of Information Display and Visualization, School of Electronic Science and Engineering, Southeast University, Nanjing, 210096, P. R-China

*Corresponding author's email: fahimullah320@ seu.edu.cn

Citation

Fahim Ullah. Experimental studies on re-hydration of vacuum freeze-dried Asparagus (Asparagus officinalis L) with a hydrophilic substance. Pure and Applied Biology. Vol. 10, Issue 2, pp445-457.

http://dx.doi.org/10.19045/bspab.2021.100048

\begin{tabular}{|c|c|c|}
\hline & & /2020 \\
\hline
\end{tabular}

\section{Abstract}

Vacuum freeze-drying is one of the best water removal methods, with final products of the highest quality. The solid-state of water during freeze-drying protects the primary structure and the product's shape with minimal volume reduction. As the leading quality problem of dehydrated green Asparagus, this experiment was to study the technique of improving the rehydration of dehydrated green Asparagus by adding a hydrophilic substance (Maltodextrin, sucrose, salt) and controlling two ways in the process of vacuum freeze-drying. The mixed solution was soaked at the rate of three different concentration ratios, i.e., 1 (10\%), 2 (15\%), and 3 (20\%) for maltodextrin, sucrose, and salts, respectively, using the L9 orthogonal and two-factor comparison experiment. It was concluded that increasing the mass of the Asparagus samples decreased the convective heat transfer coefficient. The evolution of drying months in the range of $1.78-4.74 \mathrm{~W} / \mathrm{m}^{2 \circ} \mathrm{C}$ was recorded for the mass of Asparagus samples. The results noted that to dry the Asparagus by vacuum freeze-dryer from 09:00 to 18:00 hour decreases the product's drying rate up to $0.011 \mathrm{~g} .\left(\mathrm{H}_{2} \mathrm{O}\right) \cdot \mathrm{g}^{-1}(\mathrm{~d} . \mathrm{m}) \cdot \mathrm{cm}^{-2} \cdot \mathrm{hr}^{-1}$ and moisture level up to $8 \%$. The study results noted that the pre-freezing condition was $23^{\circ} \mathrm{C}$ with the frozen time of 4 hours, which could remarkably improve the vacuum freeze-dried green asparagus rehydration. Finally, from the results, it was recommended that, from the actual production, to save energy, reduce costs; $23^{\circ} \mathrm{C}$ was better for the precooling temperature with the pre-freezing time was 4 hours for drying green Asparagus.

Keywords: Green Asparagus; Hydrophilic Substance; Rehydration; Vacuum Freeze-Drying

\section{Introduction}

Green Asparagus is also an extremely perishable vegetable. Freshly harvested Asparagus deteriorates quickly, which results in a short shelf life under normal postharvest handling at room temperature. Drying is one of the most methods used for preservation.
The drying of agricultural products has always been of great importance for preserving food by human beings. It is a primary preservation method and applies to a wide range of industrial and agricultural products. Adedeji et al. [1] reported that Asparagus (Asparagus officinalis L.) is 
commonly grown in temperate climates worldwide perennial plant with $100-150 \mathrm{~cm}$ tall, stout stems and soft vegetation. Asparagus's essential ingredients are energy, proteins, vitamins, fats, carbohydrates, etc. necessary in food with high nutritional value in the kitchen [2]. It is not only used to add food palatability, but it is also widely used in medicines, bakery products, wine and meat products, a soap product, etc. [3].

Asparagus is the most important cash crop globally, cultivated in China, Pakistan, Indian, Afghanistan, Uzbekistan, Japan, and Indonesia [4, 5]. An et al. [6] stated that the People Republic of Chain producer 17 million tons a year of Asparagus and $45 \%$ of the total world's Asparagus contributing. Nearly half of the total production of Asparagus consumed as white and red Asparagus. In contrast, the remaining 30\% converted into dry Asparagus for medicinal purposes, and $20 \%$ used as seed material [7]. Agricultural product drying has a vital role in preserving and shelf-life improvement after harvesting [8]. In developing countries, sundrying is a popular, effective, and economical method for drying food and herbal products. Sun-drying is a common food preservation technique used to control agricultural products' moisture content [9]. Traditionally, herbs, like Asparagus dried in the open sun, depend on sunshine availability and require ample drying space and long drying time [10].

Green Asparagus is very resistant to the storage; after harvesting of 1-2days, it will lose water, rot, and lose nutritional values [11]. The traditional processing method is to process green Asparagus into canned or frozen products. The research on the drying of green Asparagus is less; the main reason is that the drying of green Asparagus is reduced, which is also the key to dehydrated green quality asparagus [12]. The moisture content of the solar-dried unpeeled Asparagus found to be $7.0 \%$, unlike that of sun-drying, which could attain only $17.0 \%$ moisture content [13]. Other researchers [14, 15] have reported the drying behavior of Asparagus at four different drying air temperatures, i.e., $25^{\circ} \mathrm{C}, 35^{\circ} \mathrm{C}$, and $45^{\circ} \mathrm{C}$, with the fixed air velocity of $1.3 \mathrm{~m} / \mathrm{s}$. The study results concluded that moisture content reduced from $87 \%$ to $6 \%$, with a temperature of $45^{\circ} \mathrm{C}$ on a wet basis.

Blanching is the pre-treatment method used to arrest a few physiological processes. It helps in the inactivation of the enzymes, acceleration of drying rate, and reduced quality loss. It expels intercellular air from the tissues and softens it (16). Generally, the blanching of fruits and vegetables is done by heating in steam or hot water. Drying, a routine food preservation technique, is a crucial aspect of food processing [16, 17]. The dried product's shelf life has been demonstrated to extend by reducing the water concentration at which microbiological and physicochemical deterioration is limited [18]. The drying method and processing conditions significantly affect the color, texture, density, porosity, and sorption characteristics of plant materials [19]. Therefore, the same plant raw material may yield a completely different product, depending on the type of drying and extraction methods employed [20].

In the past, it was mainly through controlling the soaking temperature, soaking time, and water consumption to improve the rehydration of dehydrated vegetables. In recent years, researchers have started to develop the ratio of rehydration in the view of pre-treatment. The pore of dehydrated vegetable infiltrated into maltodextrin, sucrose, and salt molecule, improving the rehydration ratio of dehydrated through the immersion of hydrophilic material green asparagus, which was much better than using the physical method alone. 


\section{Material and Methods}

Description of the experimental procedure We took fresh green asparagus samples from the local market accessible in Nanjing, China, and washed them with distilled water for experimental work. The samples were cut cylindrical tube with a length of $3.6 \mathrm{~mm}$ and a $1.4 \mathrm{~mm}$ in diameter and placed on the weighing balance. Ullah et al. [21] reported that they are usually tiny and intense, growing 10-20 $\mathrm{mm}$ long and 3-7 $\mathrm{mm}$ in diameter. Asparagus samples were cut into cylindrical shapes with a length of $4 \mathrm{~mm}$, and a diameter of $6 \mathrm{~mm}$ was also reported [22]. The data was recorded from 9:00 to 18:00 in June, July, and August 2016. The asparagus specimens were put in trays and placed on the digital electronic balance in each drying hour to determine water content discharge. After each hour of drying, the experimental observation data were recorded, as well as the evaporation was scrapped with the attained constant weight of the samples. The literature observed that the Asparagus dried from its average initial moisture content of $89 \%$ to the final moisture content of $8 \%$ [23].

The data obtained from the measurements of Asparagus weight used for drying kinetics and analysis of Asparagus in terms of moisture removal rate, and the drying was discontinued. The samples' constant weight was achieved. The difference in weight directly gave the quantity of water content evaporated during any time interval. Wet and dried Asparagus samples are shown in (Fig. 1). The moisture removal rate was expressed on a dry basis. Equation 1 was used for the determination of the moisture removal rate of the product. The moisture ratio of Asparagus during the drying can be obtained from equation 2. While the dry matter is the dry weight of the Asparagus can be calculated using equation 3, evaluated [24]. For determining the area of fruits, inch tape was used for recording the diameter before and after each hour of drying with the use of equation 4, reported [25]. Therefore drying rate is the evaporation of water content from the products in unit area unit time. It can be calculated from the dry matter of the product how much moisture was lost during the drying. Equation 5 was used to calculate the product's drying rate each hour studied by [26]. Similarly, the symbols used in the equations, "Dm" is Dry matter (g), "Wt" wet weight $(\mathrm{g})$, " $M_{\text {initial }}$ " is Initial moisture removing rate $\left(\%\right.$, dry basis), " $W_{w}$ " is the weight of wet Asparagus (g), " $W_{d}$ " represents the weight of dry Asparagus (g), "MR" is the moisture ration (\%), "Mo" is the initial moisture content (\%, dry basis), "Me" is the equilibrium moisture content (\%, dry basis), " $\mathrm{A}_{\mathrm{p}}$ " is the cross-sectional area of the product $\left(\mathrm{cm}^{3}\right)$, " $\pi$ " constant term 3.144, "r" radius of the product $(\mathrm{cm})$, " $\mathrm{D}_{\mathrm{r}}$ " is the drying rate of the product $\left[\left(\mathrm{g}\left(\mathrm{H}_{2} \mathrm{O}\right) \cdot \mathrm{g}^{-1}(\mathrm{~d} \cdot \mathrm{m}) \cdot \mathrm{cm}^{-2} \cdot \mathrm{h}^{-}\right.\right.$ $\left.{ }^{1}\right)$ ] and " $\mathrm{D}_{\mathrm{t}}$ " denoted the drying time (hr).

$$
\begin{aligned}
& M_{\text {initial }}=\frac{W_{w}-W_{d}}{W_{d}} \times 100 \text { Eq. (1) [27] } \\
& M R=\frac{\mathrm{M}-M_{e}}{M_{o}-M_{e}} \text { Eq. (2) [28] } \\
& \begin{array}{ll}
D_{m}=W_{t}-\left(W_{t} \times M_{\text {initial }}\right) & \text { Eq. (3) } \\
A_{p}=\pi r^{2} & \text { Eq. (4) } \\
D_{r}=\frac{W_{w}-W_{d}}{D_{m} \times A_{p} \times D_{t}} & \text { Eq. (5) }
\end{array}
\end{aligned}
$$

In (Table 1) it shows the moisture removal rate data, indoor and outdoor vacuum freezedryer temperature, product temperature, the surrounding temperature of the product, and ambient temperature during the experiment.

\section{Experimental methods}

The mixed solution was soaked at the rate of three different concentration ratios, i.e., 1 (10\%), 2 (15\%), and 3 (20\%) for maltodextrin, sucrose, and salts, respectively, using the L9 orthogonal and two-factor comparison experiment. Determination of rehydration of green Asparagus with vacuum freeze-drying process, the fresh green Asparagus was selected for blanching treatment with maltodextrin's robust solution; sucrose, and salt concentrations (sodium Chloride, $\mathrm{NaCl}$ ) (29) and soaked for 
30min. In this experimental work, we used the treatment solution separately for determining the rehydration ratio. Kingsly et al., [29] studied the rapid HPLC method for the separation of isomaltulose (also known as Palatinose) from other common edible carbohydrates such as sucrose, glucose, and maltodextrins, commonly present in food and dietary supplements. After the treatment of blanching, we infiltrate the maltodextrin, sucrose, and salt molecules with the help of the osmotic process to improve the drying of green asparagus water are the best and suitable methods to increase the shelf life of products [30]. In this experiment, the concentration of maltodextrin, the sucrose level, and salt's strength was to select orthogonal analysis quality. Determination of water ratio in drying Asparagus repeated the quality times, using the $S A S$ software reported by Vesali et al. [31] the variance of quality " $L 9$ " orthogonal experiment and " $L S D$," according to the results of multiple comparisons [32].

The experiment chooses the pre-freezing temperature and the precooling time as a factor. The drying ratio product to the measuring index influences its state of dehydrated products and then influences its rehydration factors. Lin \& Brewer [33] According to the resistance method, the temperature of the eutectic point of green
Asparagus was measured. The temperature of the $5-10^{\circ} \mathrm{C}$ was lower than that of the eutectic point, so the highest temperature of green Asparagus was determined to be $23^{\circ} \mathrm{C}$. The pre-freezing time's relevant research data is less, and it needs to choose the wide horizontal range, and according to the result of the preliminary experiment. They used SAS software to analyze the variance of the experimental results and $1 / 2$ multiple comparisons, a better pre-freezing process parameter chosen according to various comparisons.

The rehydration capacity was used as a quality characteristic of the dried product [34] expressed in the rehydration rate $-\mathrm{RR}$. Approximately $2 \mathrm{~g}( \pm 0.01 \mathrm{~g})$ of the dried sample was placed in a $250 \mathrm{ml}$ laboratory glass (two analyses for each sample), $150 \mathrm{ml}$ distilled water was added, and the glass was covered and heated to boil within 3 minutes. The laboratory glass content was then gently boiled for ten (10) min more and then cooled. The cooled content was filtered for $5 \mathrm{~min}$ under vacuum and weighed. The drying ratio was calculated from equation 6. At the same time, " $W_{r}$ " is the drained weight $(\mathrm{g})$ of the rehydrated sample, and " $W_{d}$ " represents the weight of the dry sample used for rehydration [35].

$$
R R=\frac{W_{r}}{W_{d}} \text { Eq. (6) }
$$
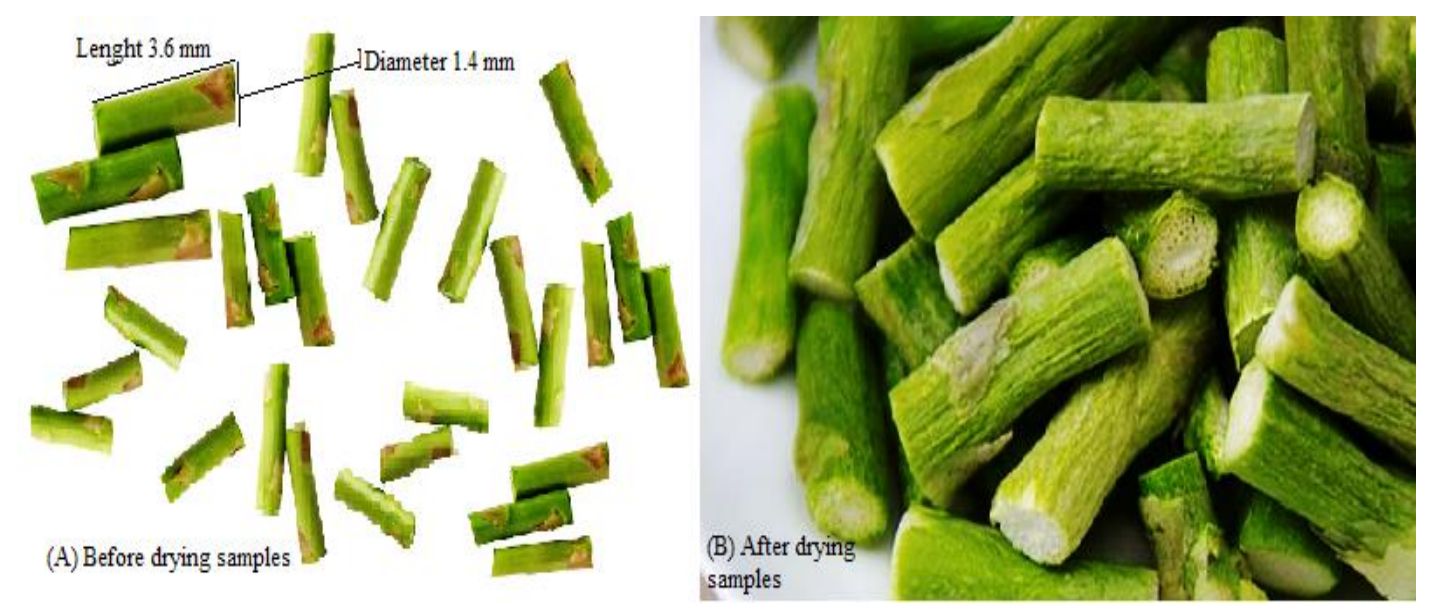

Figure 1. Show asparagus samples before drying (A) and after drying (B) 
Table 1. Shows the experimental data during re-hydration of vacuum freeze-dried asparagus samples

\begin{tabular}{|c|c|c|c|c|c|c|}
\hline Time (hr) & $\boldsymbol{T}_{\boldsymbol{i}, \boldsymbol{v}}\left({ }^{\boldsymbol{o}} \boldsymbol{C}\right)$ & $\boldsymbol{T}_{\boldsymbol{o}, \boldsymbol{v}}\left({ }^{\boldsymbol{o}} \boldsymbol{C}\right)$ & $\boldsymbol{T}_{\boldsymbol{c}}\left({ }^{\boldsymbol{o}} \boldsymbol{C}\right)$ & $\boldsymbol{T}_{\boldsymbol{e}}\left({ }^{\boldsymbol{o}} \boldsymbol{C}\right)$ & $\boldsymbol{M}_{\boldsymbol{e v p}}(\boldsymbol{g})$ & $\boldsymbol{M}_{\text {removing } \boldsymbol{r a t}}(\boldsymbol{\%} \boldsymbol{d b})$ \\
\hline 9.00 & 25.8 & 43.7 & 26.5 & 26.5 & - & - \\
\hline 10.00 & 31.2 & 57.4 & 35 & 34.3 & 8.6 & 1.6 \\
\hline 11.00 & 32.8 & 64.3 & 38.5 & 38 & 17 & 3.4 \\
\hline 12.00 & 34 & 68.8 & 40.9 & 40.4 & 26.1 & 5.7 \\
\hline 1.00 & 36 & 69.8 & 42.3 & 41.8 & 27.4 & 6.4 \\
\hline 14.00 & 36.1 & 68.2 & 42 & 41.9 & 25 & 6.2 \\
\hline 15.00 & 35.6 & 62.7 & 41 & 40.8 & 23 & 6.0 \\
\hline 16.00 & 33.2 & 54.6 & 38.3 & 38.1 & 22.2 & 6.3 \\
\hline 17.00 & 32.4 & 43.3 & 33.8 & 33.4 & 16 & 4.5 \\
\hline 18.00 & 30.7 & 41.6 & 31.9 & 32.2 & 14.7 & 4.2 \\
\hline
\end{tabular}

Note: $T_{(i, v)}$ is the temperature at vacuum freeze-dryer inlet $\left({ }^{\circ} \mathrm{C}\right), T_{(o, v)}$ is the temperature at vacuum freeze-dryer $\left({ }^{\circ} \mathrm{C}\right), T_{c}$ is the product temperature $\left({ }^{\circ} \mathrm{C}\right), T_{e}$ is the product surrounding temperature $\left({ }^{\circ} \mathrm{C}\right), M_{e v p}$ is the moisture evaporation $(\mathrm{g})$, and $M$.removing rat is the moisture removing rat in the products with the unit of $(\% \mathrm{db})$.

\section{Results and Discussion}

Under natural convection mode, the handpeeled cylindrical shaped (diameter 1.4 $\mathrm{mm}$, length $\quad 3.6$ $\mathrm{mm}$ ) mass of Asparagus samples is dry. Rect angular trays were used to conduct drying assessments of Asparagus $\mathrm{sp}$ ecimens. (Fig. 2) represents the comparison between the means of solar radiation (MSR) and the mass of the products of asparagus samples for the three months. Jamil et al. [36] studied bean moisture diffusivity and drying kinetics. They reported that the conditions of pre-freezing temperature and time would affect the size and quantity of products.

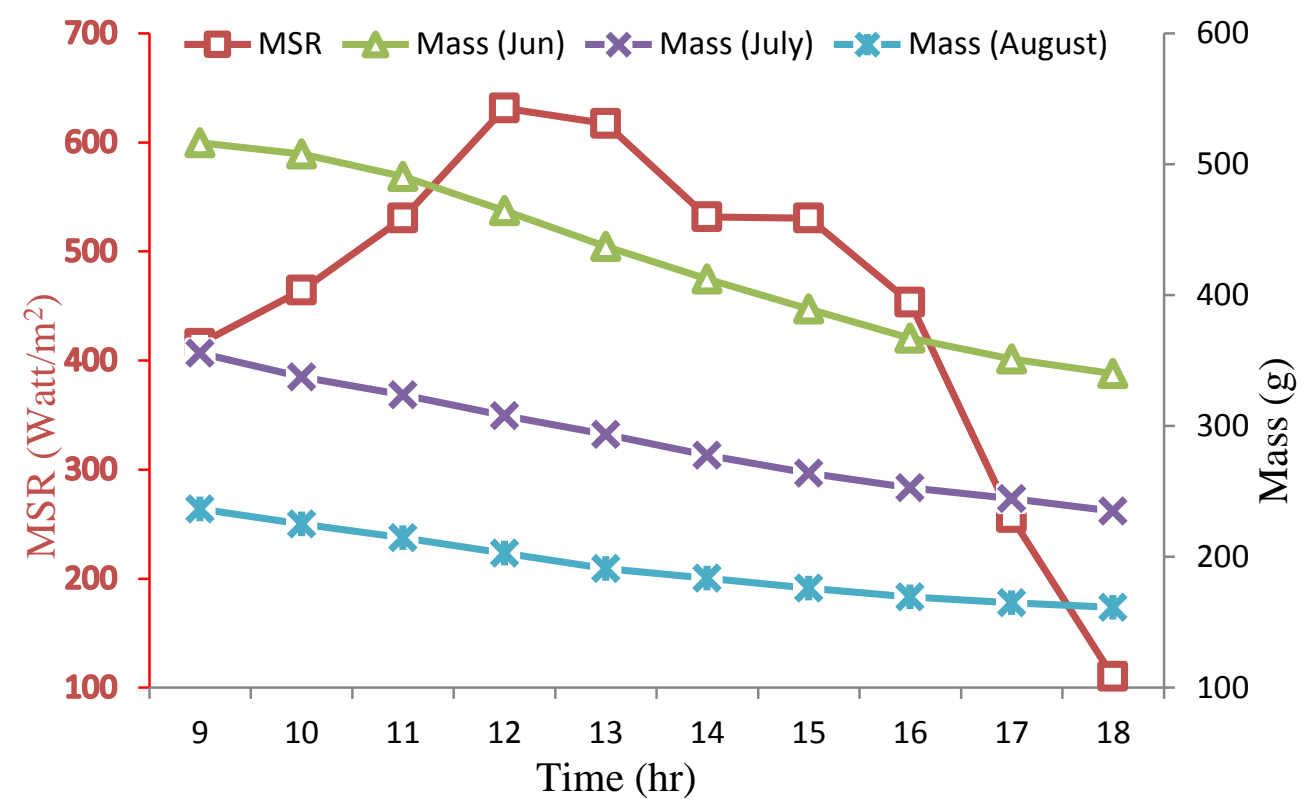

Figure 2. Comparison between the MSR and mass of the products of asparagus samples for the three months 
Solar irradiation and product mass data collected for June, July, and August 2016 at a drying time of 60-minute duration under natural heat transfer solar energy drying, as shown in (Fig. 2). It has been observed that green asparagus re-hydration increases from morning to noon and decreases from noon to evening due to swelling and diminishing trend of solar irradiation in one day. The present results are in substantial agreement with the study's previous results reported by Deshmukh et al. [37]. They said that different products' rehydration process, i.e., apples, banana, green chili, red chili, green Asparagus, etc., started increasing from morning to noon. The study results agreed with Ismail [38]. They studied that the rehydration process increased with increasing solar irradiance.

The data given in (Table 2) show the moisture removing rate, indoor and outdoor collector temperature, product and product surrounding temperature, and ambient temperature during the experiment. Table 2 shows the moisture removal rate is dependent on the total moisture present in the product mass. Hence, it has been observed that the moisture removal rate increases with an increase in green Asparagus samples mass and decreases significantly with the progression of drying days [39]. However, the moisture removal rate is also dependent on the ease of heat transfer [40]. (Fig. 3) shows the moisture lost and drying rate in Asparagus during dry. The products (Green Asparagus) were dried in the vacuum freezedryer with the process of rehydration, moisture loss, and drying rate was determined. Moisture lost in each hour of drying by a vacuum freeze-dryer is correlated with drying time. The drying rate is correlated with the change in percent moisture content to find the vacuum freeze dryer's promising performance as a drier for Asparagus's rehydration. The results show that moisture was lost with the higher temperature of the dryer. Before drying, $89 \%$ moisture was noted, and dried the product up to $8 \%$ moisture level with a dryer. Ullah and Kang [24] reported that the moisture content of the product was decreased with the highest temperature of the dryer.

Similarly, the drying rate of the apples was starting to decrease from $0.032 \mathrm{~g}\left(\mathrm{H}_{2} \mathrm{O}\right) . \mathrm{g}^{-}$ ${ }^{1}(\mathrm{~d} . \mathrm{m}) \cdot \mathrm{cm}^{-2} \cdot \mathrm{h}^{-1}$ to $0.011 \mathrm{~g}\left(\mathrm{H}_{2} \mathrm{O}\right) \cdot \mathrm{g}^{-1}(\mathrm{~d} \cdot \mathrm{m}) \cdot \mathrm{cm}^{-}$ ${ }^{2} \cdot \mathrm{h}^{-1}$ with the increasing temperature of the dryer after $10 \mathrm{hr}$ of the drying process. Kohli et al., [15] stated that the drying rate of the product was reduced with the highest temperature of the dryer. The results are similar to [41], who found that the drying is directly related to the product's moisture content.

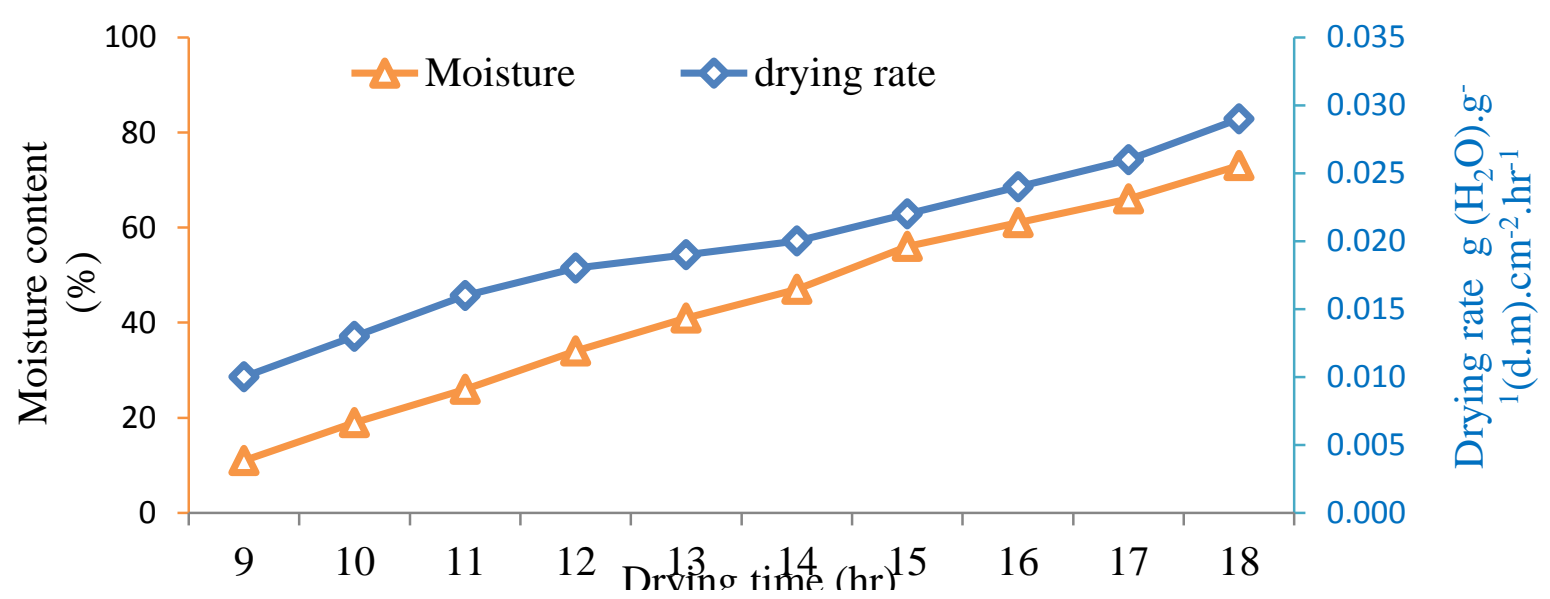

Figure 3. Shows the moisture lost and drying rate in each hour of vacuum freeze-dryer by Asparagus samples 
Table 2. Multiple comparisons of maltodextrin, sucrose, and salt concentration

\begin{tabular}{|c|c|c|c|}
\hline \multicolumn{4}{|c|}{ Maltodextrin concentration } \\
\hline A factors & $\mathbf{A 1}$ & $\mathbf{A 2}$ & $\mathbf{A 3}$ \\
\hline$\overline{x_{i}}$ & 6.052 & 6.672 & 7.041 \\
\hline Significant (5\%) & $\mathrm{b}$ & $\mathrm{ab}$ & $\mathrm{a}$ \\
\hline \multicolumn{4}{|c|}{ Sucrose concentration } \\
\hline B factors & $\mathbf{B 1}$ & $\mathbf{B 2}$ & $\mathbf{B 3}$ \\
\hline$\overline{x_{i}}$ & 6.627 & 6.111 & $\mathrm{a}$ \\
\hline Significant (5\%) & $\mathrm{ab}$ & $\mathrm{b}$ & $\mathrm{a}$ \\
\hline \multicolumn{2}{|c|}{ Salt concentration } \\
\hline C factors & $\mathbf{C 1}$ & $\mathbf{C 2}$ & $\mathbf{C 3}$ \\
\hline$\overline{x_{i}}$ & 6.656 & 7.138 & 5.970 \\
\hline Significant $(5 \%)$ & $\mathrm{ab}$ & $\mathrm{a}$ & $\mathrm{b}$ \\
\hline
\end{tabular}

Determination of hydrophilic matter concentration

Variance analyses of orthogonal experiment results are shown in (Table 3 ). The multiple maltodextrin concentration comparisons from (Table 2) show that maltodextrin's concentration was $20 \%$ (3). The ratio of water in green Asparagus is more significant at this time; removing Asparagus has better rehydration.

Table 3. L9 Orthogonal experimental results

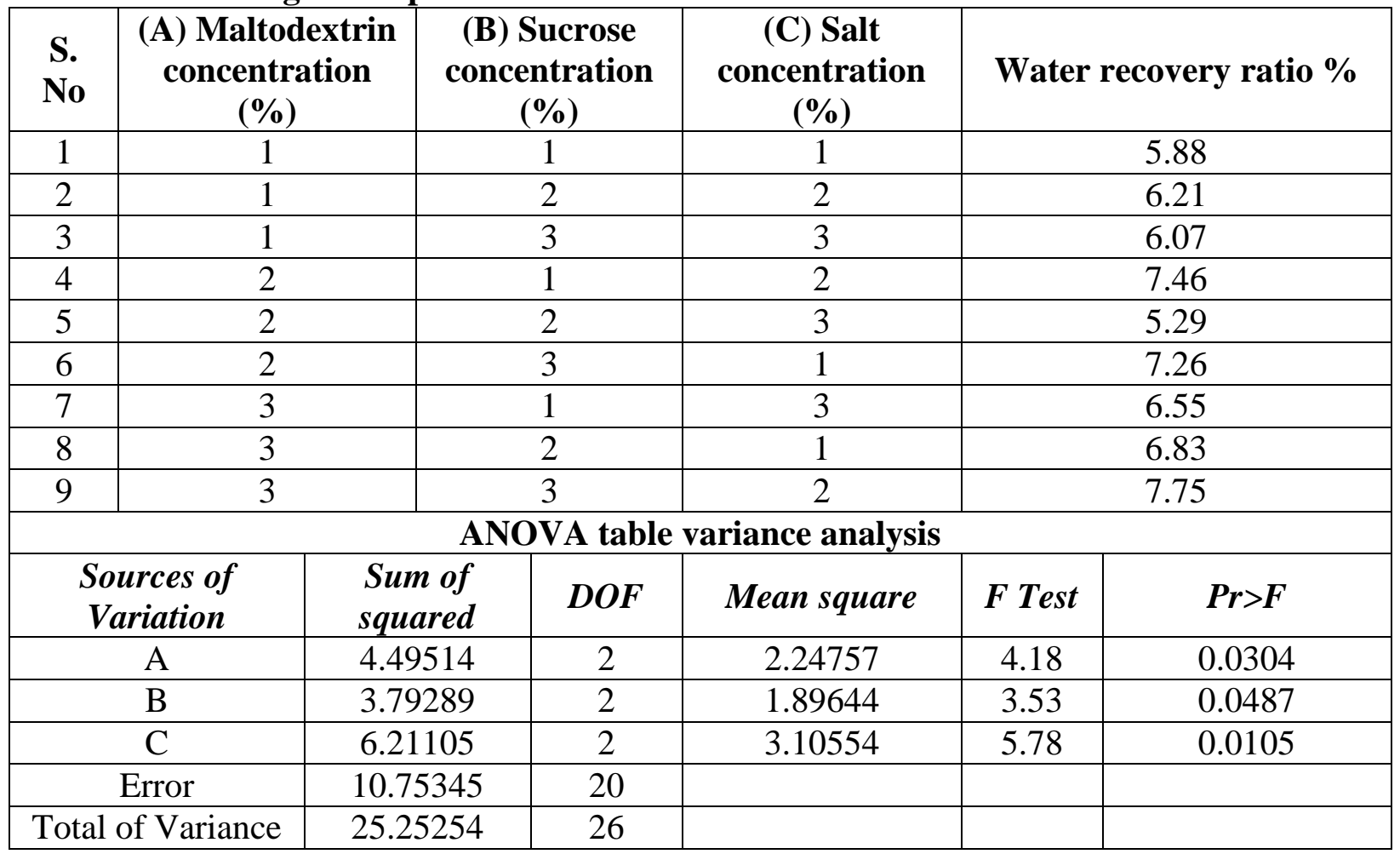

From the table results, it concluded that $20 \%$ is the preferred concentration of maltodextrin. The results reported in the literature reported by Resende et al., [42] nearly matched with the present study results. Similarly, when the $15 \%$ (2) concentration of 
maltodextrin was applied, the water recovery was not significant. The second level of concentration of $15 \%$ (2) could be used as a balanced choice for other factors. The results agree with the findings [43]. They reported that decreasing the maltodextrin's concentration ratio in the products' rehydration process, the effect on the water recovery rate was not significant. The results showed that the difference between the first $10 \%$ (1) and the third 20\% (3) levels of concentration is substantial, and the effect on the rehydration is not apparent.

Table 2 shows the multiple comparisons of maltodextrin, sucrose, and salt concentration. When the sucrose concentration was at $20 \%$ (3), which improved the asparagus' rehydration, so optimum absorption of sucrose was $20 \%$. The results are similar to the results [44]. The static results show in (Table 3) that when the sucrose concentration is the $10 \%$ (1) level, the difference between the water and the $10 \%$ (1) level is not significant, theoretically chosen as the object. Still, the influence of the other two factors should be considered. Serratosa et al., [45] conducted experimental results that are nearly matched with the present study results. At the $20 \%$ (3) level, the ratio of rehydration was significantly different, and the effect on the water recovery was not noticeable. The multiple salt concentration comparisons from (Table 2) show that salt's frequency is $15 \%$ (2). The ratio of green Asparagus is higher than the average value, so, to improve the rehydration of dehydrated products, a better salt concentration should selected as $15 \%$. These results are in agreement with the findings [46]. They reported that the concentration ratio of salt for the rehydration process of different products was $17 \%$. Therefore, when the salt concentration was $10 \%$ (1) level, the proportion of water to the (2) level was not significant and could be used in balance with the other two factors. Singh et al., [47] reported that study results contradict the present study results. When the salt concentration was at the (3) level $20 \%$, the rehydration effect was not significant, as shown in (Table 3).

Determination of the concentration of hydrophilic substances found in preliminary experiments, when the frequency of maltodextrin was low, mostly under $10 \%$ concentration, there was little effect on the drying green Asparagus [48]. The main reason was that the low concentration maltodextrin's osmotic pressure was not enough to spread the maltodextrin to the inside of the material, only on the paste's surface. As a result, when the green Asparagus is dried and reused, the dextrin's surface first absorbs water to expand, instead of preventing it from spreading to the inside [49]. When the concentration of maltodextrin is more significant, especially when it is greater than $45 \%$, the material is easily absorbed and melted during the dry process, resulting in shrinkage and deformation. Also, the dry products in the maltodextrin are very easy to moisture absorption, so that the storage becomes difficult, and there is too sticky feeling [50]. So in the appropriate concentration range, you can choose a higher concentration of maltodextrin, according to the results of multiple comparisons, the final determination of maltodextrin concentration of $20 \%$ [51]. Sucrose and salt are added to the maltodextrin to increase the solution's osmotic pressure [17]. However, the addition of sucrose and salt will affect the taste of dehydrated green Asparagus, after the experiment found that the sweet and salty ratio of $4: 3$ is more appropriate, so sucrose concentration of $20 \%$, the salt concentration of $15 \%$ [52]. It is more suitable to be considered the final process parameter, whether from improving the rehydration or from a sweet-salty angle. 


\section{Determination of pre-freezing process conditions}

The independence of the Eutectic Point of the pre-freezing cooling curve of green Asparagus is shown in (Fig. 4). As the temperature drops, the figure shows that the resistance changes very little; when the temperature drops to $-11^{\circ} \mathrm{C}$ to $-13^{\circ} \mathrm{C}$, the resistance value suddenly increased. Due to the early freeze, green Asparagus inside there is a lot of water present, more charged ions can be moved freely, and with the temperature [53]. Most of the green asparagus water is converted to ice crystals, and when the temperature drops to $-11^{\circ} \mathrm{C}$ to $13^{\circ} \mathrm{C}$, the green Asparagus is frozen, and the resistance value suddenly increases [54]. Therefore, from the experimental result, the eutectic point temperature range for the green Asparagus is noted up to $-11^{\circ} \mathrm{C}$ to $-13^{\circ} \mathrm{C}$.

The results and analysis of the two factors of the water recovery ratio shown in (Table 4). They are using SAS software to analyze the variance of water recovery effects, shown in (Table 4). From the analysis of variance results in (Table 4), it can be seen that the Pvalue of the precooling temperature is less than 0.05 , the P-value of the pre-freezing time is less than 0.01 , and these two factors have a significant or significant effect on the

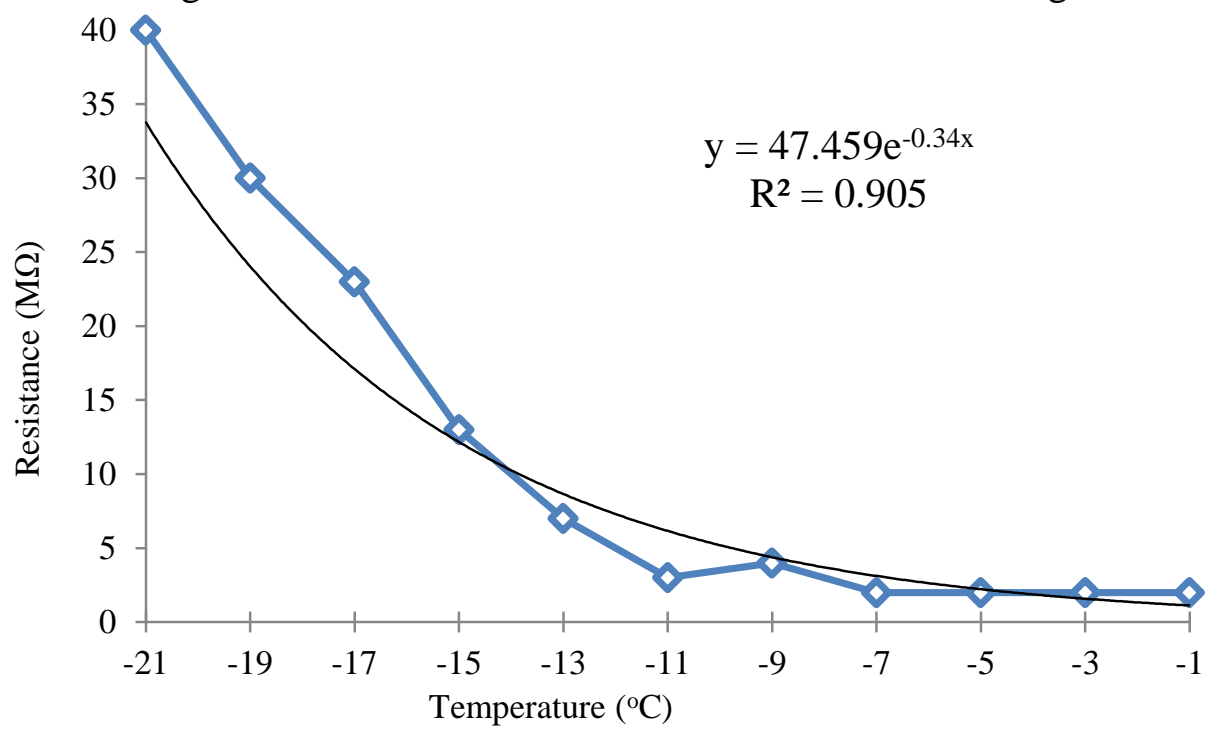

Figure 4. Eutectic point of the pre-freezing cooling curve of green Asparagus rehydration ratio of the dehydrated green Asparagus [23]. Among them, pre-time is an essential factor, and the precooling temperature is the secondary factor. They are using the method of LSD to compare the prefreezing temperature and the pre-freezing time, taking the rehydration ratio of the dehydrated green Asparagus as the object of study, the proper conditions of precooling determined according to the results [14].

The multiple comparisons of the pre-freezing temperature (Table 5) show that when the pre-freezing temperature $-20\left({ }^{\circ} \mathrm{C}\right)$ and -30 $\left({ }^{\circ} \mathrm{C}\right)$, the green asparagus ratio is higher than the average is no significant difference between the two. So the precooling temperature is $23^{\circ} \mathrm{C}$ and $-30^{\circ} \mathrm{C}$, which is beneficial to improving the drying ratio of the green Asparagus [44]. When the pre-freezing temperature is the second level, the water recovery ratio's mean value is lower. There is a significant difference with the other two levels, which has no significant effect on improving the rehydration of the dehydrated green Asparagus.

The multiple comparisons of pre-freezing time are shown in (Table 5). When the prefreezing time is 6 hours and 4 hours, the green asparagus ratio is higher, and the difference between them is not significant.

$$
\begin{gathered}
y=47.459 e^{-0.34 x} \\
R^{2}=0.905
\end{gathered}
$$


Table 4. Experimental comparison results of two factors of water recovery ratio

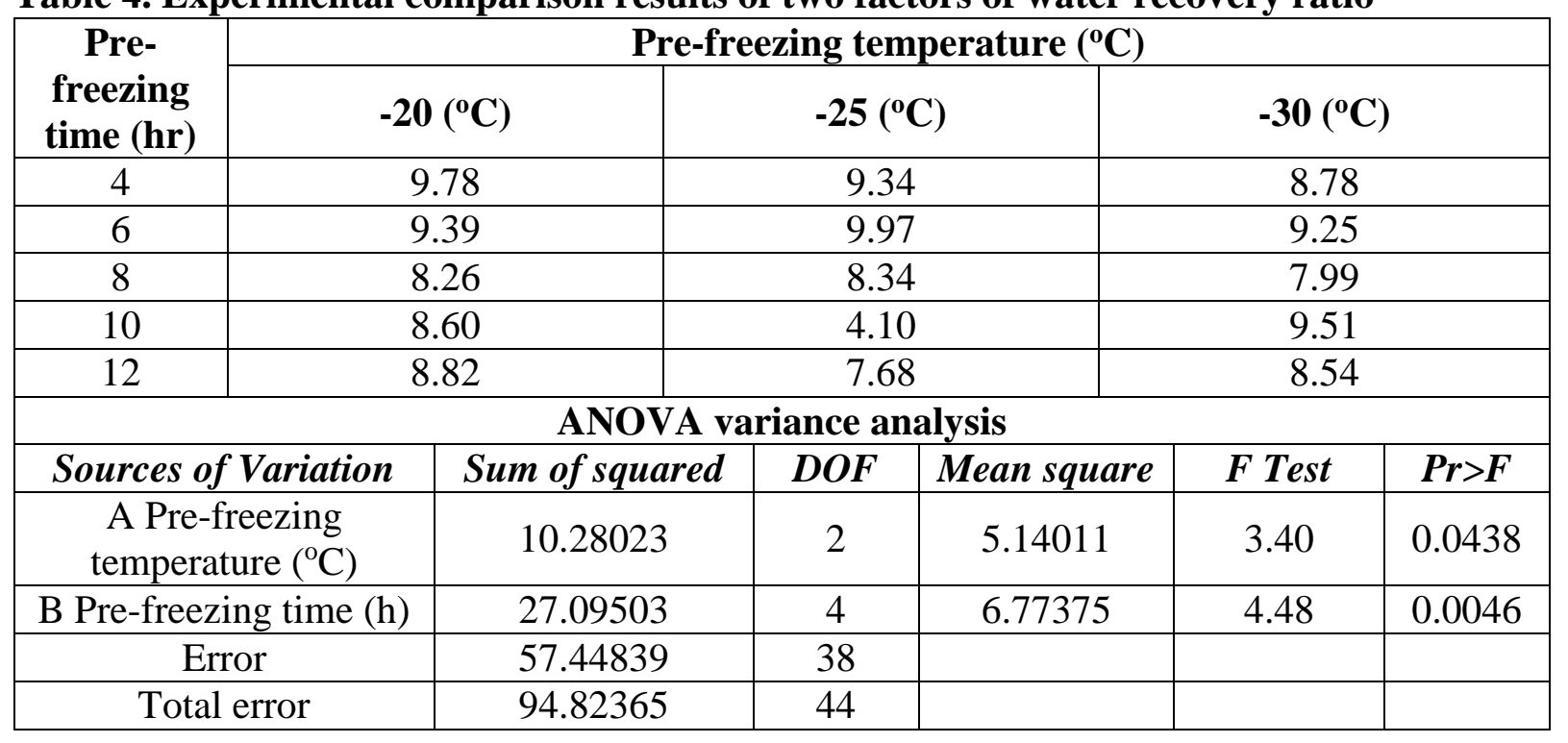

Table 5. Multi-comparison of pre-freezing temperature and pre-freezing time

\begin{tabular}{|c|c|c|c|c|c|}
\hline \multicolumn{6}{|c|}{ Pre-freezing temperature } \\
\hline A factors & \multicolumn{2}{|l|}{ A1 } & \multicolumn{2}{|l|}{ A2 } & $\mathbf{A 3}$ \\
\hline$\overline{x_{i}}$ & \multicolumn{2}{|l|}{8.967} & \multicolumn{2}{|l|}{7.886} & 8.815 \\
\hline Significant (5\%) & \multicolumn{2}{|l|}{$\mathrm{a}$} & \multicolumn{2}{|l|}{$\mathrm{b}$} & $\mathrm{a}$ \\
\hline \multicolumn{6}{|l|}{ Pre-freezing time } \\
\hline B factors & B1 & B2 & B3 & B4 & B5 \\
\hline$\overline{\bar{x}_{i}}$ & 9.301 & 9.531 & 8.197 & 7.401 & 8.350 \\
\hline Significant (5\%) & $a b$ & $\mathrm{a}$ & $\mathrm{bc}$ & $\mathrm{c}$ & $\mathrm{bc}$ \\
\hline
\end{tabular}

So the pre-freezing treatment of 6 hours and 4 hours can improve the dehydrated Asparagus [36]. 6 hour is the first choice of parameters, the remaining three levels and above two levels of water ratio difference is significant, to improve the drying of green Asparagus. For analyzing the above factors, 6 hours and 4 hours is the pre-freeze time [20].

\section{Conclusion}

The research reported in this paper includes the evaluation of re-hydration of vacuum freeze-dried Asparagus (Asparagus officinalis l) with hydrophilic substance (Maltodextrin, sucrose, salt) and moisture removing rate for the mass of asparagus samples. The experiment finally determined that, in the pre-treatment process, the green Asparagus soaked with $20 \%$ maltodextrin,
$20 \%$ sucrose, and $15 \%$ salts in a mixed solution with the Pre-freezing temperature of $23^{\circ} \mathrm{C}$ and 4 hours was the pre-freezing time can improve the absorption of dehydrated green Asparagus. The following observations and conclusions noted form the results:

From the experiment results, the parameters of the pre-freezing process improving the ratio of water recovery.

The experimental results noted that the convective heat transfer coefficient varies from 1.78 to $4.74 \mathrm{~W} / \mathrm{m}^{2 \circ} \mathrm{C}$ for green asparagus samples.

The precondition of selecting the prefreezing process of precooling temperature was noted $23^{\circ} \mathrm{C}$ and $-30^{\circ} \mathrm{C}$ with the prefreezing time 6 hours and 4 hours.

The experiment results recommended that, from the actual production, to save energy, 
reduce costs; $23^{\circ} \mathrm{C}$ was better for the precooling temperature. The pre-freezing time was 4 hours for the drying of green Asparagus.

\section{Authors' contributions}

Conceived and designed the experiments: $\mathrm{F}$ Ullah, Performed the experiments: F Ullah, Analyzed the data: F Ullah, Contributed materials/ analysis/ tools: F Ullah, Wrote the paper: F Ullah.

\section{Acknowledgments}

We extend our thanks to all the research contributors to support and provide research facilities for this study.

\section{References}

1. Adedeji AA, Gachovska TK, Ngadi MO \& Raghavan GSV (2008). Effect of pretreatments on drying characteristics of okra. Dry Technol 26: 1251-1256.

2. Aghbashlo M, Kianmehr $\mathrm{MH}$ \& Arabhosseini A (2008). Energy and exergy analyses of thin-layer drying of potato slices in a semi-industrial continuous band dryer. Dry Technol 26: 1501-1508.

3. Al-Khuseibi M, Sablani S, Conrad OP (2007). Comparison of water blanching and high hydrostatic pressure effects on drying kinetics and quality of potato. Dry Technol 23: 2449-2461.

4. Alibas I (2007). Microwave, air and combined microwave-air-drying parameters of pumpkin slices. LWT Food Sci Technol 40: 1445-1451.

5. Alibas I (2009). Microwave, vacuum, and air drying characteristics of collard leaves. Dry Technol 27: 1266-1273.

6. An D, Arntfield SD, Beta $\mathrm{T}$ \& Cenkowski S (2010). Hydration properties of different varieties of Canadian field peas (Pisum sativum) from different locations. Food Res Int 43(2): 520-5.

7. Eze J \& Agbo K (2011). Comparative studies of sun and solar drying of peeled and unpeeled ginger. Am J Sci Ind Res 2:
136-143.

8. Ibrahim A \& Dincer I (2015). A solar desalination system: Exergetic performance assessment. Energy Convers Manag 379-92.

9. Sharma A, Chen CR \& Nguyen VL (2009). Solar energy drying system: A review. Renew Sustain Energy Rev 1185-1210.

10. Bingol G, Pan Z, Roberts JS, Devres YO \& Balaban MO (2008). Mathematical modeling of microwave-assisted convective heating and drying of grapes. Int J Agric Biol Eng 1: 46 - 54.

11. Chauhan A \& Srivastava K (2009). Optimizing drying conditions for vacuum-assisted microwave drying of green peas (Pisum sativum L.). Dry Technol 27: 761-769.

12. Hatamipour MS \& Mowla D (2006). Drying behaviour of maize and green peas immersed in fluidized bed of inert energy carrier particles. Food Bioprod Process 84(C3): 220-2206.

13. Hossain MA \& Bala BK (2007). Drying of hot chilli using solar tunnel drier. Sol Energy 81: 85-92.

14. Hoque M, Bala B, Hossain M \& Uddin M (2013). Drying Kinetics of Ginger Rhizome (Zingiber officinale). Bangla $J$ Agri Res 38(2): 301-319.

15. Kohli D, Shahi NC \& Kumar A (2018). Drying kinetics and activation energy of Asparagus root (Asparagus Racemosus Wild.) for different methods of drying. Curr Res Nutr Food Sci 6(1): 191-202.

16. Stela J, Ibrahim M, Milan M, Darko V, Mate B \& Jasmina L (2009). Influence of Drying Procedure on Colour and Rehydration Characteristic of Wild Asparagus. Czech J Food Sci 27(3): 171-177.

17. İbrahim D \& Fergun K (2011). Drying and Rehydration Behaviors of Convection Drying of Green Peas. Dry Technol 29. 
18. Jangam S, Joshi V, Mujumdar A \& Thorat B (2008). Studies of dehydration of sapota (Achras zapota). Dry Technol 26: 369-77.

19. Prachurjya D, Tapan D, Moonmee B, Munmi K, Kabita Gogoi SJI \& JK (2016). Pesticidal Plants of Northeast India. In: Purkayastha J. (eds). In: Bioprospecting of Indigenous Bioresources of North-East India. Springer, Singapore.

20. Miao Q, Hengjun J, Gerui R, Jianying H \& Wang X (2013). Effect of chitosan coatings on postharvest green asparagus quality. Carbohydr Polym 92(2): 202732.

21. Ullah F, Kang M, Hassan L, Li N, Yang J, Wang X \& Mansoor KK (2016). Impact of drying method of figs with small-scale flat-plate solar collector. World J Eng 13(5): 407-412.

22. Suleyman K (2006). Performance analysis of new design solar air collectors for drying application. $J$ Renew Energy 32: 1645-60.

23. Ullah F, Mansoor KK, Khan M, Hassan L \& Hasrat K (2016). Impact of the dehydration process on guava by using of the parabolic trough solar concentrator. Pakistan J Food Sci 26(2):92-7.

24. Ullah F \& Kang M (2017). Impact of air flow rate on drying of apples and performance assessment of parabolic trough solar collector. Appl Ther Eng 127: 275-280

25. Matthew GN, Jason N, Peter F, Gina Y, Linda M \& House JD (2017). Determination of the protein quality of cooked Canadian pulses. Food Sci Nutr 5(4): 896-903.

26. Loha C, Das R, Choudhury B \& Pradip KC (2012). Evaluation of air drying characteristics of sliced ginger (Zingiber officinale) in a forced convective cabinet dryer and thermal conductivity measurement. J Food Process Technol DOI: 10.4172/2157-7110.1000160

27. Yadav AK \& Singh SV (2014). Osmotic dehydration of fruits and vegetables: a review. J Food Sci Technol 51(9): 165473.

28. Crha T \& Pazourek J (2020). Rapid HPLC Method for Determination of Isomaltulose in the Presence of Glucose, Sucrose, and Maltodextrins in Dietary Supplements. Foods 9: 1164.

29. Kingsly RP, Goyal RK, Manikantan MR \& Ilyas SM (2007). Effects of pretreatments and drying air temperature on drying behavior of peach slice. Int $J$ Food Sci Technol 42:65-69.

30. Doymaz I (2010). Effect of citric acid and blanching pre-treatments on drying and rehydration of Amasya red apples. Food Bioprod Process 88(2-3): 124132.

31. Vesali F, Gharibkhani M \& Komarizadeh MH (2011). An approach to estimate moisture content of apple with image processing method. Aust $J$ Crop Sci 5(2): 111-115.

32. Aktaş M, Ceylan I \& Yilmaz S (2009). Determination of drying characteristics of apples in a heat pump and solar dryer. Desalination 239(1-3): 266-75.

33. Lin S \& Brewer MS (2005). Effects of blanching method on the quality characteristics of frozen peas. J Food Qual 28: 350-360.

34. Seiiedlou S, Ghasemzadeh HR, Hamdami N, Talati F \& Moghaddam M (2010). Convective drying of apple: Mathematical modeling and determination of some quality parameters. Int J Agric Biol 12(2): 171178.

35. Gharehbeglou BA, Rad AH, Hoseini SS, Pour HT \& Rad AHEP (2014). Investigating of drying kinetics and mathematical modeling of turnip. CIGR $J$ 16(3):194-204. 
36. Jamil AA, Osama A \& Ahmed AS (2014). Design and Performance Assessment of a Parabolic Trough Collector. Jordan J Mech Ind Eng 8:1.

37. Deshmukh AW, Varma MN, Yoo CK \& Wasewar KL (2014). Investigation of Solar drying of ginger (Zingiber officinale): emprical modelling, drying characteristics, and quality study. Chinese J Eng 7.

38. İsmail O (2016). Effect of drying methods on drying characteristic. $J$ energy 2(2):801-6.

39. Markowski M, Bondaruk J \& Blaszczak W (2009). Rehydration behavior of vacuum-microwave-dried potato cubes. Dry Technol 27: 296-305.

40. Azoubell PM \& Francinaide OS (2008). Optimisation of osmotic dehydration of 'Tommy Atkins' mango fruit. Int J Food Sci Technol 43(7): 1276- 1280.

41. Pardeshi I, Arora S \& Borker P (2009). Thin-layer drying of green peas and selection of a suitable thin-layer drying model. Dry Technol 27: 288-95.

42. Resende O, Corréa PC, Jarén C \& Moure AJ (2007). Bean moisture diffusivity and drying kinetics: A comparison of the liquid diffusion model when taking into account and neglecting grain shrinkage. Spanish J Agric Res 5: 51-58.

43. Roberts JS, Kidd DR \& Padilla-Zakour $\mathrm{O}$ (2008). Drying kinetics of grape seeds. J Food Eng 89: 460-465.

44. Sacilik K, Elicin AK \& Unal G (2006). Drying kinetics of Uryani plum in a convective hot-air dryer. J Food Eng $76: 362-368$.

45. Serratosa MP, Lopez-Toledano A, Medina M \& Merida J (2008). Drying of Pedro Ximenez grapes in chamber at controlled temperature and with dipping pretreatments. Changes in the color fraction. J Agric Food Chem 56: 10739
10746.

46. Simal S, Mulet A, Tarrazo J \& Rossello C (1999). Drying models for green peas. Food Chem 55:121 - 128.

47. Singh S, Raina CS, Bawa AS \& Saxena DC (2006). Effect of pretreatments on drying and rehydration kinetics and color of sweet potato slices. Dry Technol 24:1487-1494.

48. Sobukola O (2009). Effect of pretreatment on the drying characteristics and kinetics of okra (Abelmoschus esculetus (L.) moench) slices. Int J Food Eng 5(2): 9.

49. Tarhan S, Ergunes G \& Taser OF (2006). Selection of chemical and thermal pretreatment combination to reduce the dehydration time of sour cherry (Prunus cerasus L.). J Food Process Eng 29: 651663.

50. Xanthopoulos G, Lambrinos Gr \& Manolopoulou H (2007). Evaluation of thin-layer models for mushroom (Agaricus bisporus) drying. Dry Technol 25: 1471-1481.

51. Pariascai J, Miyazaki T, Hisaka H, Nakagawa H \& Sato T (2000). Effect of modified atmosphere packaging (MAP) and controlled atmosphere (CA) storage on the quality of snow pea pods (Pisum sativum L. var. saccharatum). Postharvest Biol Technol 21.

52. Menges H \& Ertekin C (2006). Modeling of air drying of Hacihaliloglu-type apricots. J Sci Food Agric 86: 279-91.

53. Kostaropoulos AE \& Saravacos GD (1995). Microwave pre-treatment for sun-dried raisins. J Food Sci 60: 344347.

54. İbrahim D \& Fergun K (2011). Drying and Rehydration Behaviors of Convection Drying of Green Peas. Dry Technol 29(11). 